\title{
Hybrid Films with (Trimethoxysilylpropyl) Methacrylate (TMSM), Poly (Methyl methacrylate) PMMA and Tetraethoxysilane (TEOS) Applied on Tinplate
}

\author{
Sandra Raquel Kunst ${ }^{\text {a* }}$, Gustavo Aalberto Ludwig , Henrique Ribeiro Piaggio Cardoso ${ }^{\mathrm{a}}$, \\ Joseane Andrade Santana ${ }^{\mathrm{b}}$, Victor Hugo Vitorino Sarmento ${ }^{\mathrm{b}}$, Célia de Fraga Malfatti ${ }^{\mathrm{a}}$ \\ ${ }^{a}$ Departamento de Metalurgia - PPGEM, Laboratório de Pesquisa em Corrosão - LAPEC, \\ Universidade Federal do Rio Grande do Sul-UFRGS, Av. Bento Gonçalves, 9500, \\ prédio 75, CEP 91501-970, Porto Alegre, RS, Brasil \\ ${ }^{\mathrm{b}}$ Instituto de Química - IQ, Universidade Federal de Sergipe - UFS, Itabaiana, SE, Brasil
}

Received: June 24, 2013; Revised: April 6, 2014

\begin{abstract}
The tetraethoxysilane (TEOS) influences morphological and electrochemical properties of hybrid films by function of concentration. Moreover, the use of acetic acid as a catalyst in the sol enables a more complete hydrolysis of the silane precursors due to the fact that the acetic acid goes through a more complete ionization when in aqueous solution. The aim of this paper is to study the effect of the concentration of tetraethoxysilane (TEOS) on the protective properties of the film on tinplate substrate. The tinplate was coated with a hybrid film obtained from a sol-gel method constituted of the following alkoxide precursors: 3 - (trimetoxisililpropil) methacrylate (TMSM) and poly(methyl methacrylate) PMMA. The effect of tetraethoxysilane (TEOS) concentration has also been evaluated. The films hydrolysis was performed at a $\mathrm{pH}$ value of 3.0 using acetic acid as a catalyst. The films were obtained by dip-coating process, cured for 3 hours at $160^{\circ} \mathrm{C}$. The film morphology was evaluated by SEM and profilometry. The electrochemical behavior of the films was evaluated by open circuit potential monitoring, potentiodynamic polarization and electrochemical impedance spectroscopy. The film hydrophobicity was determined by contact angle measurements. The studied films have shown good performance as to corrosion resistance on tinplate. The hybrid film which was obtained through the addition of an excessive amount of TEOS (T3A3) showed increased thickness. Nevertheless, due to an intense densification of the film, promoted by the addition of TEOS, a formation of cracks was registered, thereby compromising the corrosion resistance.
\end{abstract}

Keywords: hybrid films, tinplate, corrosion

\section{Introduction}

According to NBR 6665 (ABNT 2006) standard, tinplate is a laminated carbon steel sheet, coated with a tin layer by an electrodeposition process ${ }^{1}$. Tinplates have the capability of forming good corrosion resistance and weldability ${ }^{2}$. The main application of tinplates is on food packaging manufacturing and other packages ${ }^{3}$. The presence of tin oxides and the passivation coating on the surface of tinplates are characteristics of their quality. Tinplates usually show a complete or partial coverage of tin oxides $\left(\mathrm{SnO}_{\mathrm{x}}\right)$, mainly $\mathrm{SnO}$ and $\mathrm{SnO}_{2}$, including their hydrated forms. The presence of oxides in excess could modify the appearance and the weldability of the tinplate and its capacity of receiving organic coatings ${ }^{4}$. Nowadays, packages are covered by superficial treatments, based on chromate layers, thereby generating excellent corrosion resistance ${ }^{5}$. Chromatization, or chrome conversion layering, also enables the adhesion between the metal and the posterior paint layer. Although these treatments are easy to apply and economically viable $e^{6,7}$, these processes are carcinogenic and toxic to environment ${ }^{8}$, which has given rise to severe governmental regulations 9 .

*e-mail: tessaro.sandra@gmail.com
Hence, alternative non-toxic treatments have been developed in the last few years to substitute them. Among possible alternatives, pretreatments based on siloxanePMMA have demonstrated promising results, attracting attention of industries. These hybrids films improve corrosion resistance ${ }^{10}$ and adhesion properties of organic layers. Moreover, they reduce the environmental impacts compared to the chromatization process ${ }^{11}$, and promote an excellent anchorage on metal surface of tinplate for posterior paint application, which can be done by the releasing of silicone from functional siloxanes using an ultraviolet cure ${ }^{12}$.

Researchers have developed siloxane-PMMA films with hydrochloric acid and found that hybrid films presented good corrosion resistance and could be used as a pretreatment for the corrosion protection of tin coated steels ${ }^{13,14}$. However, the change in formulation influences the film formation characteristics of the coating. For instance, siloxane-PMMA with acetic acid leads to better hydrolysis conditions and subsequent cross-linking than $\mathrm{HCl}$. This indicates that films which are prepared with acetic acid undergo more complete ionization when in aqueous solution, i.e., with a 
complete hydrolysis of the silane precursors, such as TEOS (tetraethoxysilane) ${ }^{15}$.

Silica films based on tetraethoxysilane (TEOS), obtained through the sol-gel process, are practical to prepare due to their low preparation temperature, low cost of processing, and the ability to obtain homogeneous films on large area substrates. However, TEOS-based films are generally brittle due to the incorporation and evaporation of chemicals such as water $\left(\mathrm{H}_{2} \mathrm{O}\right)$, methanol $\left(\mathrm{CH}_{3} \mathrm{OH}\right)$ and ethanol $\left(\mathrm{CH}_{3} \mathrm{CH}_{2} \mathrm{OH}\right)$ after baking or thermal treatment. To overcome these limitations, new hybrid materials have been studied with the aim of obtaining coatings with micrometer thicknesses devoid of cracks $^{16}$.

The aim of this work is to study the effect of tetraethoxysilane (TEOS) concentration has also been evaluated. The films hydrolysis was performed at a $\mathrm{pH}$ value of 3.0 using acetic acid as a catalyst. The tinplate was coated with a hybrid film obtained from a sol-gel method constituted by the alkoxide precursors: 3 - (trimethoxysilylpropyl) methacrylate (trimetoxisililpropil) methacrylate (TMSM) and tetraethoxysilane (TEOS) followed by radical polymerization of poly(methyl methacrylate) $\mathrm{P}(\mathrm{MMA})$, and it was evaluated the tetraethoxysilane (TEOS) concentration effect. The films were obtained through a dip-coating process and cured for 3 hours at $160{ }^{\circ} \mathrm{C}$.

\section{Experimental Procedure}

\subsection{Substrate treatment}

Tinplates with dimensions of $20 \mathrm{~mm}$ x $40 \mathrm{~mm}$ were obtained from an industrial (donated by Metallurgic Mococa SP, Brazil), rinsed with acetone and dried. Then, the plates were degreased by a 10 -min immersion in neutral detergent at $70{ }^{\circ} \mathrm{C}$, washed and dried.

\subsection{Elaboration of siloxane-PMMA hybrid films}

All chemicals used were commercially available. The hybrid films were obtained from a tinplate substrate from a sol-gel method constituted by the following silane precursors: TMSM $\left(\mathrm{C}_{10} \mathrm{H}_{20} \mathrm{O}_{5} \mathrm{Si}\right.$, Fluka $)$ and TEOS $\left(\mathrm{C}_{8} \mathrm{H}_{2} \mathrm{OO}_{4} \mathrm{Si}\right.$, Aldrich) with the addition of MMA $\left(\mathrm{C}_{5} \mathrm{H}_{8} \mathrm{O}_{2}\right.$, Fluka), which was distilled to remove the polymerization inhibitor (hydroquinone) and impurities, and stored in a freezer prior to use. The thermal initiator benzoyl peroxide (BPO - $\mathrm{C}_{14} \mathrm{H}_{10} \mathrm{O}_{4}$, Reagen) was recrystallized from ethyl alcohol. The sol-gel method was employed in the preparation of hybrid organic-inorganic materials, where, in the synthesis of the inorganic phase, precursors TMSM and TEOS were mixed at $60{ }^{\circ} \mathrm{C}$ for 1 hour. Hydrolysis was performed at $\mathrm{pH}$ value of 3.0 using acetic acid as a catalyst and ethanol and water as solvents. The organic phase consisted of simple homogenization of MMA and BPO at room temperature. Finally the two solutions (inorganic and organic) were mixed. The hybrid sol used in the films was prepared using the following molar ratios: TEOS:MPTS $=0,1,2$ for samples named as T0A3, T1A3 and T2A3, respectively; MPTS:MMA = 1:6; H2O:Si = 3.5:1; ethanol: $\mathrm{H} 2 \mathrm{O}=1: 2$ and BPO:MMA =1:100. The Table 1 shows the description of samples used.

The films were obtained through a dip-coating process using a Marconi MA765 device. The substrates were dipped in the hybrid sol for 1 minute, withdrawn at a constant rate of $14 \mathrm{~cm} \cdot \mathrm{min}^{-1}$ and then air-dried for approximately $10 \mathrm{~min}$. Subsequently, the coated substrates were heat treated at a temperature of $160{ }^{\circ} \mathrm{C}$ for 3 hours under a heating rate of $5{ }^{\circ} \mathrm{C} \cdot \mathrm{min}^{-1}$. This treatment increases the degree of polymerization since it promotes the formation of free radicals from $\mathrm{C}=\mathrm{C}$ bonds existing in TMSM and MMA.

\subsection{Characterization of siloxane-PMMA hybrid films}

Scanning electron microscopy (SEM) in a JEOL-JSM 5800 device with an acceleration voltage of $20 \mathrm{keV}$ was used to evaluate the thickness, by cross section, as well as the morphology of hybrid films.

The surface microroughness was evaluated in a contact profilometer (PRO500 3D).

The film hydrophobicity was determined by the contact angle measurement from the sessile drop method using equipment developed by the research laboratory in corrosion (LAPEC) of UFRGS. The contact angle was determined by an image analysis software (also developed by the mentioned laboratory).

The corrosion performance of the films was evaluated by open circuit potential (OCP) monitoring, potentiodynamic polarization and electrochemical impedance spectroscopy (EIS) measurements, in a $0.05 \mathrm{M} \mathrm{NaCl}$ solution. For the electrochemical characterization, a three-electrode cell was used, with platinum as the counter electrode and SCE as the reference electrode. The work electrode area was $0.626 \mathrm{~cm}^{2}$. The OCP monitoring and potenciodynamic polarization curves were performed in a potentiostat PAR 273. The OCP was monitored for the first hour of immersion in the electrolyte before the polarization curves and the EIS measurements. The polarization curves were measured with a scan rate of $1 \mathrm{mV} . \mathrm{s}^{-1}$, ranging from 200 $\mathrm{mV}$ (under OCP) to $400 \mathrm{mV}$ (above OCP). The device used for the EIS measurements was a potentiostat (Omnimetra

Table 1. Description of the samples studied.

\begin{tabular}{ll}
\hline \multicolumn{1}{c}{ Sample } & \multicolumn{1}{c}{ Description } \\
\hline Tin plate & Tinplate without coating \\
T0A3 & Tinplate hybrid film coated with siloxane-PMMA without addition of TEOS with acetic acid and $\mathrm{pH}=3 \mathrm{de}$ TEOS. \\
T1A3 & $\begin{array}{l}\text { Tinplate coated with hybrid film with addition of TEOS (level 1), acetic acid and } \mathrm{pH}=3 \\
\text { T3A3 }\end{array}$ \\
& $\begin{array}{l}\text { Tinplate coated with hybrid film with addition of TEOS (level 3, increased concentration of TEOS in the level 1), } \\
\text { and acetic acid } \mathrm{pH}=3\end{array}$ \\
\hline
\end{tabular}


Mod. PG-05) coupled to a Solartron 125 frequency response analyzer. The amplitude of the EIS perturbation signal was $10 \mathrm{mV}$, and the frequency studied ranged from $100 \mathrm{kHz}$ to $10 \mathrm{mHz}$.

\section{Results and Discussion}

\subsection{Morphological characterization}

Figure 1 shows the SEM micrographs for the films studied: T0A3 (without TEOS addition), T1A3 (with TEOS addition of level 1) and T3A3 (with TEOS addition of level 3). The morphological appearance of the obtained hybrid films shows the presence of discontinuities in the T0A3 sample (Figure 1a), with cracks and delamination in the T3A3 hybrid film (Figure 1c). This behavior is due to the formation of a porous, brittle ceramic structure ${ }^{17}$ after TEOS hydrolysis and cross-linking. Thus, the addition of a higher amount of TEOS contributed to the irregular coverage of the film. In T1A3 (Figure 1b) a homogeneous film can be seen, showing no discontinuities and no fissures. This proportion of TEOS was sufficient to produce the synergistic effect of the presence of TMSM and TEOS precursors in the hybrid film ${ }^{14}$.

The thickness of the films was determined by the analysis of cross section images obtained by SEM (Figure 2). It can be observed that the sample showing the highest thickness was that with the greatest addition of TEOS (T3A3) (Figure 2c). This is associated with a higher content of silanol groups (the inorganic phase) due to the greater amount of TEOS in the film. Previous studies carried out by Si NMR for these unsupported films showed an increase in the degree of condensation as a function of TEOS/TMSM ratio increase, obtaining values from $78 \%$ to $85 \%$. This increase is manly due to heterocondensation between TEOS ans TMSM which results in siloxane crosslinking and consequently, in the formation of a dense hybrid network contributing to the thickness and adhesion of films ${ }^{18}$. However, it was verified that the sample T0A3 (Figure 2a) showed a greater film thickness than the T1A3 (Figure 2b). Such unusual behavior must be analyzed further.

According to Figure 3 the tin plate substrate (Figure 3a) and T0A3 hybrid film (Figure 3b) (without TEOS addition) showed similar roughness values. As it can be observed, the T1A3 hybrid film (Figure 3c) showed the lowest value of roughness, i.e., this film has formed a homogeneous and regular coverage on tinplate, as observed by SEM analysis in Figure 1b. The sample with a higher TEOS addition (T3A3) showed a high roughness and a difference on the roughness values between peak and valley of $8.72 \pm 0.65 \mu \mathrm{m}$, as shown on Table 2. Figure $3 d$ indicates that the film thickness is irregular, which is related to the different color patterns in the phase scale. The regions with irregular amplitude defects are related either to direct exposure of the substrate, or to regions which are coated with thinner films. These regions may constitute conductive pathways to electrolyte penetration.

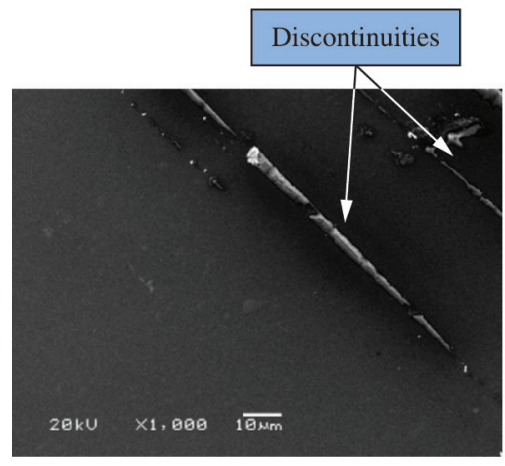

(a)

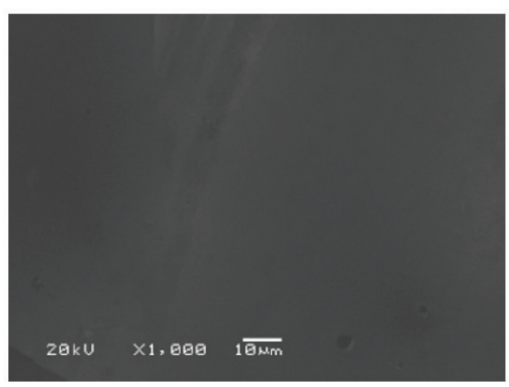

(b)

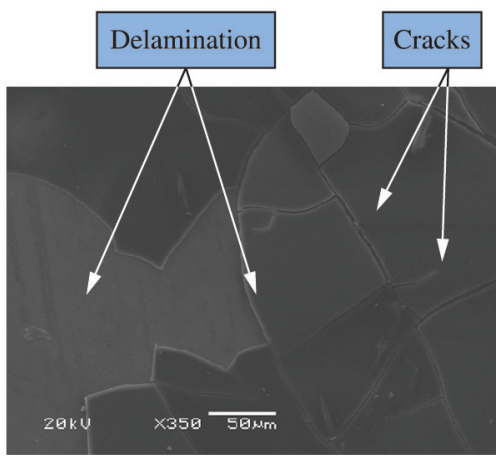

(c)

Figure 1. Micrographs obtained from SEM of hybrid films: (a) T0A3, (b) T1A3 and (c) T3A3.

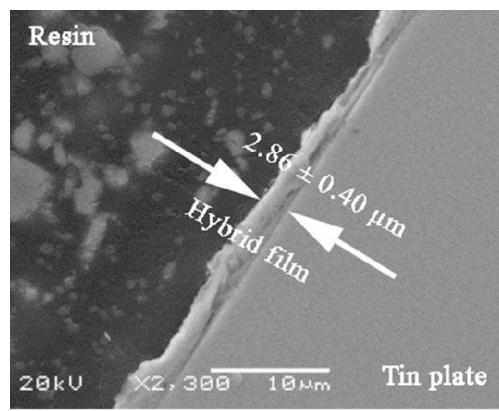

(a)

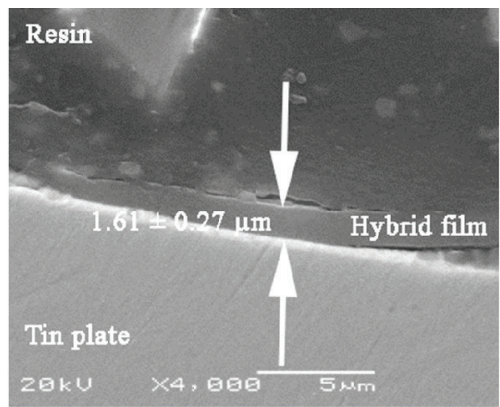

(b)

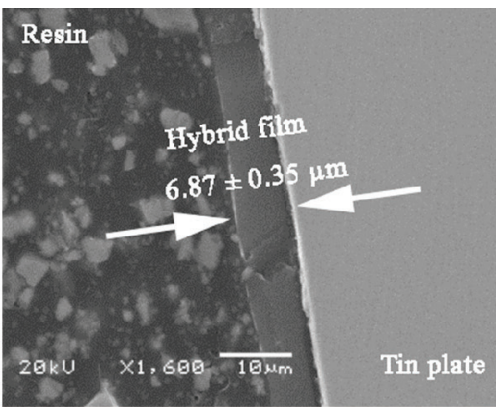

(c)

Figure 2. Cross section micrographs obtained by SEM: (a) T0A3, (b) T1A3 and (c) T3A3. 


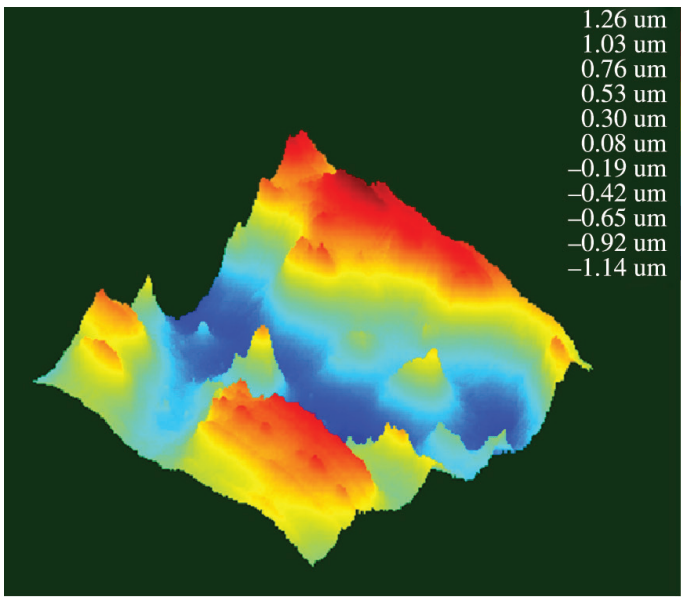

(a)

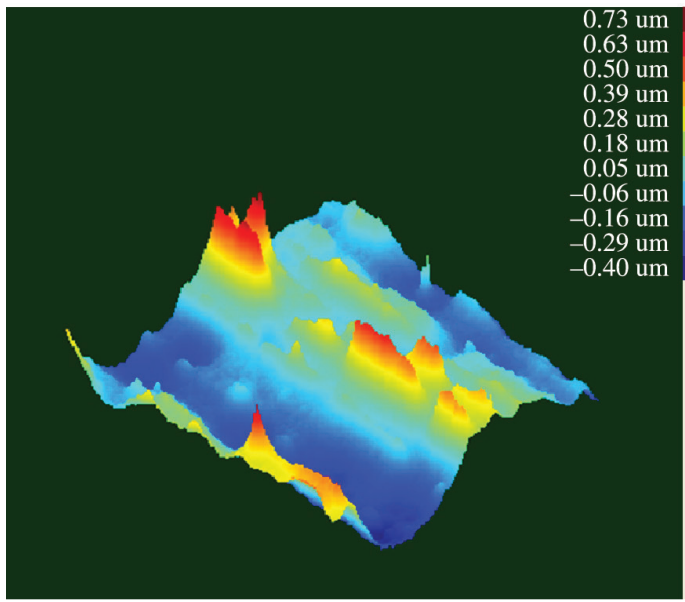

(c)

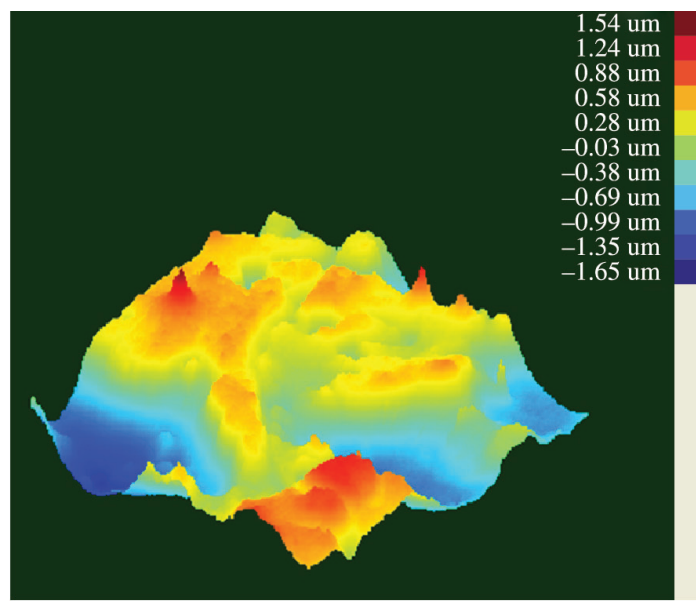

(b)

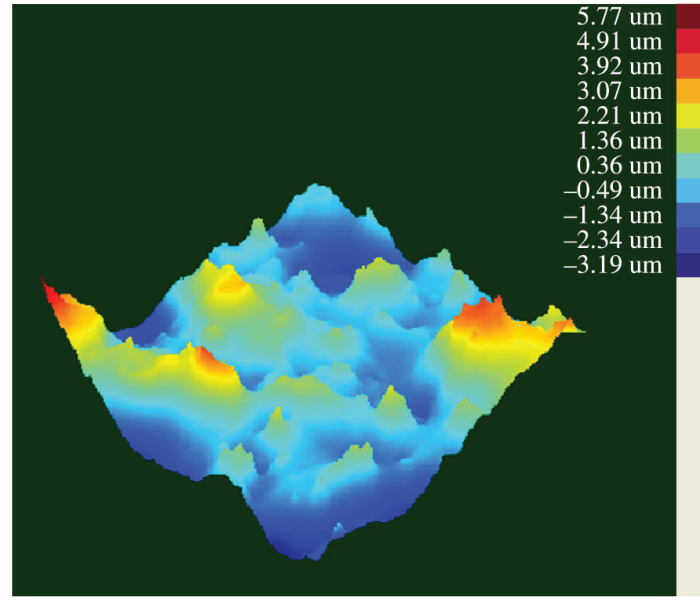

(d)

Figure 3. Tridimensional images obtained by profilometry for: (a) tinplate, (b) T0A3, (c) T1A3 and (d) T3A3.

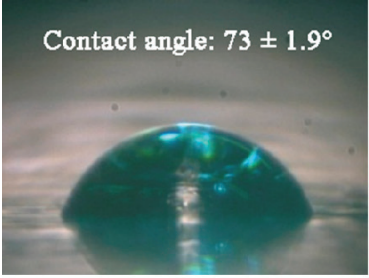

(a)

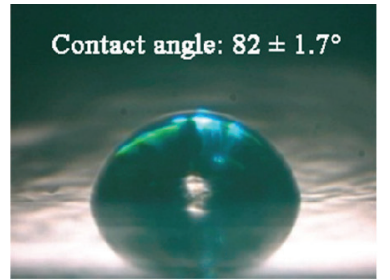

(b)

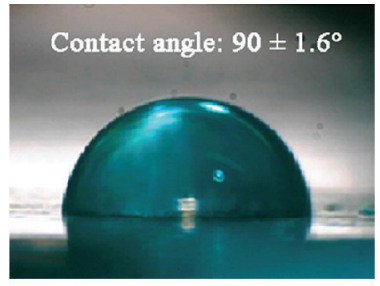

(c)

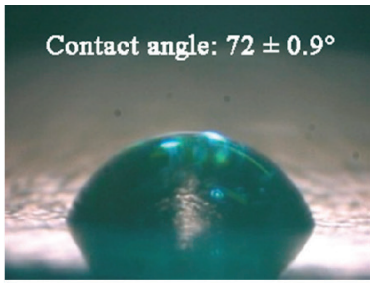

(d)

Figure 4. Images obtained for the contact angle determination by the sessile drop method: (a) tinplate, (b) T0A3, (c) T1A3 and (d) T3A3.

Table 2. Roughness values of the samples determined by profilometry analysis.

\begin{tabular}{lccc}
\hline \multirow{2}{*}{ Samples } & \multicolumn{3}{c}{ Surface Roughness } \\
\cline { 2 - 4 } & Ra $(\mu \mathbf{m})$ & Rms $(\mu \mathbf{m})$ & $\begin{array}{c}\text { Peak to peak } \\
(\mu \mathbf{m})\end{array}$ \\
\hline Tinplate & $0.43 \pm 0.27$ & $0.51 \pm 0.31$ & $2.40 \pm 0.83$ \\
T0A3 & $0.55 \pm 0.31$ & $0.68 \pm 0.44$ & $5.29 \pm 1.63$ \\
T1A3 & $0.15 \pm 0.42$ & $0.18 \pm 0.28$ & $1.13 \pm 0.22$ \\
T3A3 & $1.01 \pm 0.16$ & $1.30 \pm 0.13$ & $8.72 \pm 0.65$ \\
\hline
\end{tabular}

These results are in agreement with those obtained by SEM analysis (Figure 1c)

The results of the contact angle area are shown in Figure 4. The value of the contact angle obtained for tinplate is associated with the fact that this behavior is probably due to the presence of tin oxides ( $\mathrm{SnOx})$, as $\mathrm{SnO}, \mathrm{SnO}_{2}$ and its hydrated forms, which confer a complete or partial coverage of the surface, increasing substrate hydrophobicity ${ }^{19}$. The sample without addition of TEOS (T0A3) showed an intermediate angle value that relates to the curing process, 
in which hydrophobic siloxane bonds are formed in the film network, hindering water penetration.

Nevertheless, neither the hydrolysis of the precursors, nor the cross-linking (polycondensation) is complete during curing. The T1A3 hybrid film showed the highest contact angle value and, consequently, lower wettability. This behavior is related to the formation of more siloxane groups in the system with TEOS, forming a more compact network, preventing the absorption of water, and making the film more hydrophobic. The regular morphology can be observed on Figure $1 \mathrm{~b}$. The silane films present a hydrophobic character when sufficiently cross-linked. Hence, the contact angle of a well-cross linked film is of approximately $90^{\circ}$. However, this value becomes smaller after immersion in an aqueous solution, indicating that the $\mathrm{Si}-\mathrm{O}-\mathrm{Si}$ bond is not stable $\mathrm{e}^{20}$. Since these links are not stable, the $\mathrm{Si}-\mathrm{O}-\mathrm{Si}$ reactions can suffer from hydrolysis, again forming the $\mathrm{Si}-\mathrm{OH}$ hydrophilic groups so that water and ions can penetrate and react with the interface ${ }^{21}$. Consequently, more hydrophobic silane films provide better protection to metals, as the barrier and adhesion properties can vary with the time of air or aqueous exposure, due to the susceptibility of the $\mathrm{Si}-\mathrm{O}-\mathrm{Si}$ bonds to hydrolysis reactions.

The T3A3 hybrid film showed the highest wettability (lowest contact angle values), among the studied samples. This behavior can be associated to the hydrophilic behavior made by TEOS addition in excess ${ }^{22}$ and also to discontinuities present in this film.

\subsection{Electrochemical characterization}

According to Figure 5a, OCP values for all hybrid films (T0A3, T1A3 and T3A3) shifted to more noble values of potential compared to tinplate. This can be related to the formation of a barrier layer between substrate and media by the hybrid films. The results of the polarization curves (Figure 5b) showed that the hybrid films siloxane-PMMA (T0A3 and T1A3) promoted an increase in polarization resistance ( $\mathrm{Rp}$ ) and a decrease in corrosion current density $\left(i_{\text {corr }}\right)$ values related to tinplate, evidencing the protective behavior of these films. The siloxane-PMMA hybrid film obtained with a higher addition of TEOS (T3A3) showed greater thickness (Figure 2c). However, due to intense densification of the film promoted by the addition of TEOS, and consequently the increase of $\mathrm{SiO}_{2}$, a formation of cracks can be noticed, thereby compromising the corrosion resistance. XPS results performed by Sarmento et al. showed that $\mathrm{SiO}_{2}$ content in these hybrid films increased between 13,7 and $19.0 \%$ with increasing TEOS/TMSM ratio, which can promote the formation of cracks due to their brittle nature ${ }^{18}$.

Figure 6 shows the Nyquist and Bode diagrams for the T0A3, T1A3 and T3A3 samples, obtained for 96 hours of immersion in a $0.05 \mathrm{M} \mathrm{NaCl}$ solution. As per the Nyquist diagrams, the T1A3 hybrid film (Figure 6b) shows higher resistance values compared to other samples. On the other hand, according to Bode diagrams it is possible to observe a phenomenon associated with the high frequency barrier effect only for T1A3 samples at all immersion times analyzed. This shows the protective effect of this coating on the corrosion resistance as seen in the images after electrochemical test of Figure 7b.This phenomenon may be associated with the fact that this sample presents a more homogeneous film without cracking due to a more effective condensation reaction, favored by sufficient amount of TEOS added to the film, which provided less hydrophilic groups due to the reaction of silanol groups. The T3A3 sample (Figure 6c) showed lower strength and impedance modulus compared to the T0A3 sample according to the results of OCP and polarization (Figure 5). The T0A3 sample presented the worst performance in the electrochemical impedance tests, as seen in the post-electrochemical tests images (Figure $7 \mathrm{a}$ ). Zaioncz et al. ${ }^{23}$ reported that the copolymerization of TMSM with the MMA monomers promotes a cross-linked hybrid structure with PMMA chains surrounding the siloxane particles. This results in a hybrid structure where the MMA radical is covalently bonded to the TMSM moieties through polymerization reactions and can only interact by weak Van der Waals forces. In this film, it was also observed a time constant in the medium to low frequency range, indicating an acceleration of the

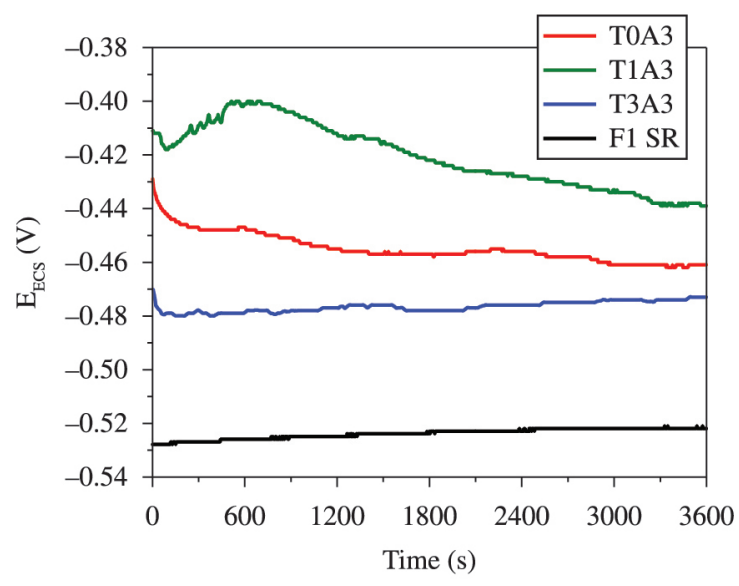

(a)

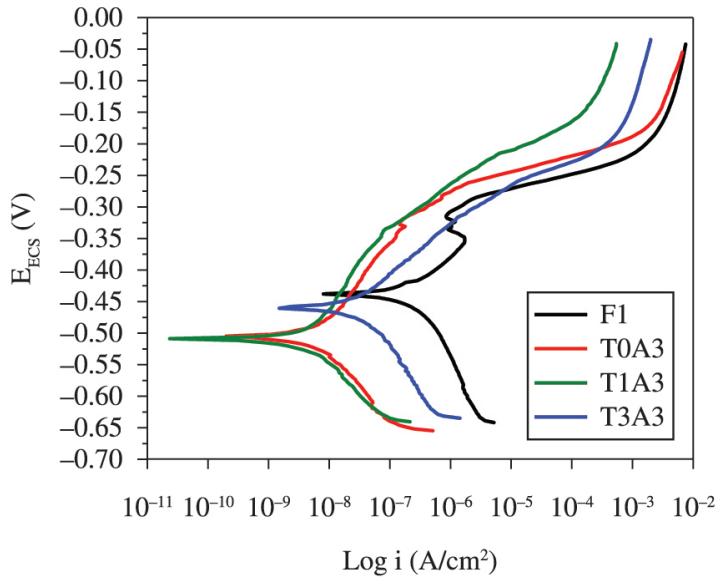

(b)

Figure 5. (a) Open-circuit potential and (b) Polarization curves in a $0.05 \mathrm{M} \mathrm{NaCl}$ solution. 

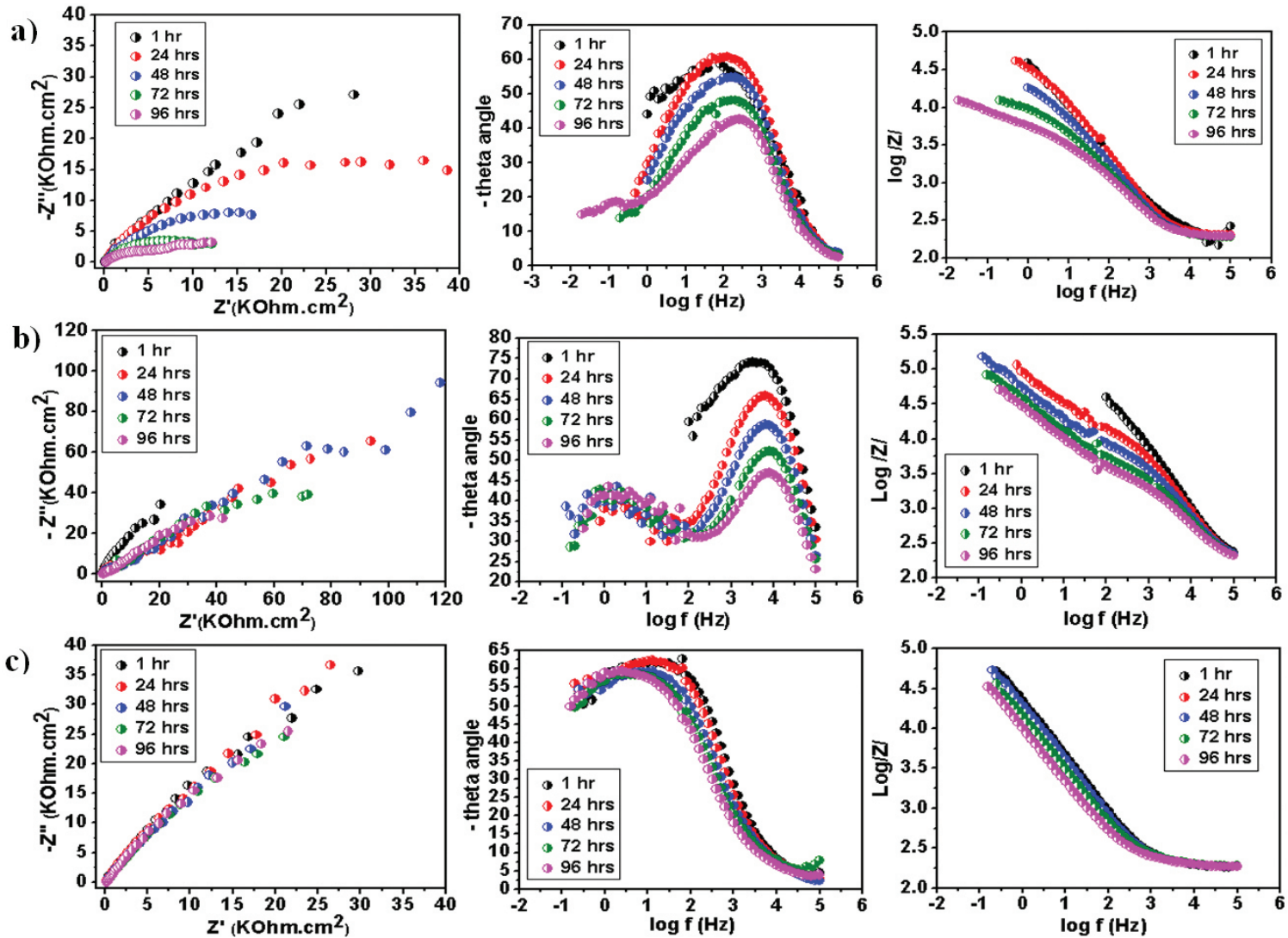

Figure 6. Nyquist and Bode diagrams obtained for: (a) T0A3, (b) T1A3 and (c) T3A3.

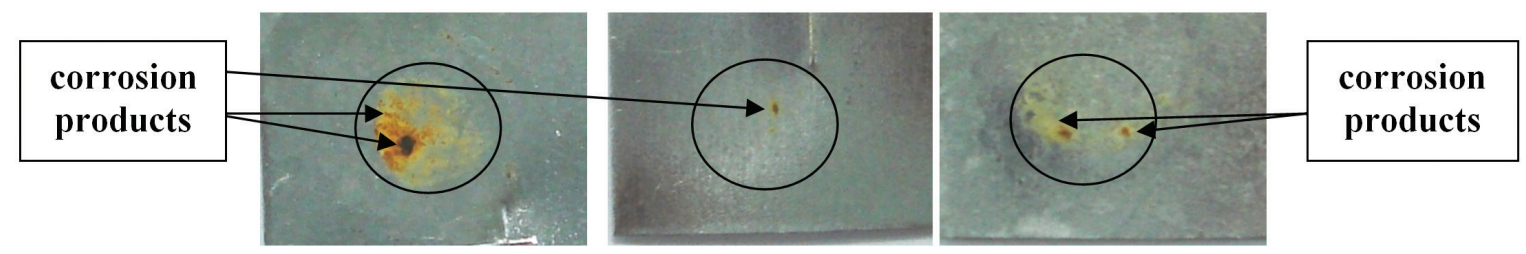

Figure 7. Digital images obtained after 96 hours in electrochemical impedance in NaCl 0,05M: (a) T0A3, (b) T1A3 and (c) T3A3.

interfacial process associated with the tin oxides on the substrate surface.

\section{Conclusion}

The results showed that the T1A3 sample presented the best performance in the electrochemical tests. For this hybrid film, the presence of cracks and discontinuities was not observed. Moreover, the T1A3 hybrid film showed the highest contact angle value and, consequently, the lowest wettability. This behavior is related to the formation of more siloxane groups in the system with TEOS, forming a more compact network, preventing the absorption of water, and making the film more hydrophobic.

The siloxane-PMMA hybrid film obtained with a higher addition of TEOS (T3A3) showed greater thickness, however, due to the formation of a porous, brittle ceramic structure after TEOS hydrolysis and cross-linking, cracks were formed, thereby compromising the corrosion resistance.

The T0A3 sample presented the worst performance in the electrochemical impedance tests as seen in the images after electrochemical tests. This is due to the film structure, where the MMA radical, covalently bonded to the TMSM moieties through polymerization reactions, interacts only by weak Van der Waals forces.

\section{Acknowledgments}

The present work was carried out with support of CAPES, a Brazilian Governmental entity focused in human resources formation. The authors are also thankful for the financial support of the Brazilian agencies: CNPq and FAPERGS. 


\section{References}

1. Filho VM. Embalagem metálica: avaliação de folhas de flandres na fabricação de latas expandidas a partir do processo stretching. [Dissertação]. São Caetano do Sul: Centro Universitário do Instituto Mauá de Tecnologia; 2007.

2. Dantas ST, Gatti JAB and Saron ES. Embalagens metálicas e a sua interação com alimentos e bebidas. Campinas: CETEA/ ITAL; 1999. $232 \mathrm{p}$.

3. Companhia Siderúrgica - CSN. Aplicações. CSN; 2005. Available from: <http://www.csn.com.br>. Access in: 25/05/2011.

4. Gatti J. Aderência de vernizes em folhas de flandres: fatores de influência. Campinas: ITAL; 2008. (Boletim de Tecnologia e Desenvolvimento de Embalagens; v. 20).

5. Cabral AM, Trabelsi W, Serra R, Montemor MF, Zheludkevich ML and Ferreira MGS. The corrosion resistance of hot dip galvanized steel and AA2024-T3 pre-treated with bis[triethoxysilylpropyl]tetrasulfide solutions doped with $\mathrm{Ce}\left(\mathrm{NO}_{3}\right)_{3}$. Corrosion Science. 2006; 48(11):3740-3758. http:// dx.doi.org/10.1016/j.corsci.2006.01.010

6. Yasuhiko E, Tomio S and Kengo T. Chromium-free water reducible rust inhibitive paint for metals. US Patent 6,960,247. 2005 Nov. 1.

7. Maze E, Mocquery $\mathrm{C}$ and Millet B. Use of $\mathrm{MoO}_{3}$ as corrosion inhibitor, and coating composition containing such an inhibitor. US Patent 7,081,157. 2006 July 25.

8. Ono S, Tsuge H, Nishi Y and Hirano SI. Improvement of corrosion resistance of metals by an environmentally friendly silica coating method. Journal of Sol-gel Science and Thecnology. 2004; 29(3):147-153. http://dx.doi.org/10.1023/ B:JSST.0000023849.33761.86

9. Environmental Protection Agency - EPA. Toxicological review of hexavalent chromiumre. EPA; 1998. Available from: <http:// www.epa.gov>. Access in: 15/12/2010.

10. Hu H, Li N, Cheng J and Chen L. Corrosion behavior of chromium-free dacromet coating in seawater. Journal of Alloys and Compounds. 2009; 472(1-2):219-224. http://dx.doi. org/10.1016/j.jallcom.2008.04.029

11. Trabelsi W, Triki E, Dhouibi L, Ferreira MGS and Montemor MF. An electrochemical and analytical assessment on the early corrosion behavior of galvanized steel pretreated with aminosilanes. Surface and Coantings Techonology. 2005; 192(23):284-290. http://dx.doi.org/10.1016/j.surfcoat.2004.04.088

12. Dóhler H, Ferenz M and Herweth S. Utilização de silanos epóxifuncionais como aditivos de aderência para revestimentos de liberação de silicone de cura por radiação catiônica. BR Patent PI0603786-0A. 2007 Ago 14.

13. Suegama PH, Sarmento VHV, Montemor MF, Benedetti AV, Melo HG and Aoki IV et al. Effect of cerium (IV) ions on the anticorrosion properties of siloxane-poly(methyl methacrylate) based film applied on tin coated steel. Electrochimica Acta. 2010; 55(18):5100-5109. http://dx.doi.org/10.1016/j. electacta.2010.04.002

14. Sakai RT, Cruz FMDL, Melo HG, Benedetti AV, Santilli CV and Suegama PH. Electrochemical study of TEOS, TEOS/ MPTS, MPTS/MMA and TEOS/MPTS/MMA films on tin coated steel in $3.5 \% \mathrm{NaCl}$ solution. Progress in Organic Coatings. 2012; 74(2):288-301. http://dx.doi.org/10.1016/j. porgcoat.2012.01.001

15. Marino IG, Lottici PP, Bersani D, Raschellà R, Lorenzi A and Montenero A. Micro-Raman monitoring of solventfree TEOS hydrolysis. Journal of Non-Crystalline Solids. 2005; 351(6):495-498. http://dx.doi.org/10.1016/j. jnoncrysol.2004.11.023

16. Kunst SR, Santos RF, Vieira D, Oliveira CT, Vitorino VH and Malfatti CF. Elaboration and characterization of siloxanePMMA hhybrid films on tinplate substrates. Materials Science Forum. 2012; 727:1610-1615. http://dx.doi.org/10.4028/www. scientific.net/MSF.727-728.1610

17. Zhang X, Wu Y, He S and Yang D. Structural characterization of sol-gel composites using TEOS/MEMO as precursors. Surface and Coatings Technology. 2007; 201(12):6051-6058. http:// dx.doi.org/10.1016/j.surfcoat.2006.11.012

18. Sarmento VHV, Schiavetto MG, Hammer P, Benedetti AV, Fugivara CS, Suegama PH et al. Corrosion protection of stainless steel by polysiloxane hybrid coatings prepared using the sol-gel process. Surface and Coatings Technology. 2010; 204(16-17):2689-2701. http://dx.doi. org/10.1016/j.surfcoat.2010.02.022

19. Xia D, Song S, Wang J, Bi H, Jiang Y and Han Z. Corrosion behavior of tinplate in $\mathrm{NaCl}$ solution. Transactions of Nonferrous Metals Society of China. 2012; 22(3):717-724. http://dx.doi.org/10.1016/S1003-6326(11)61236-3

20. Flis J and Kanoza M. Electrochemical and surface analytical study of vinyl-triethoxy silane films on iron after exposure to air. Electrochimica Acta. 2006; 51(11):2338-2345. http:// dx.doi.org/10.1016/j.electacta.2005.01.065

21. Ooij WJV, Zhu D, Stacy M, Seth A, Mugada T and Gandhi J. Corrosion protection properties of organofunctional silanes: an overview. Tsinghua Science Technology. 2005; 10(6):639-664. http://dx.doi.org/10.1016/S1007-0214(05)70134-6

22. Cairú A and Mittal KL. V-resistant and superhydrophobic self-cleaning surfaces using sol-gel process. Netherlands: Brill; 2009.

23. Zaioncz S. Relationships between nanostructure and dynamic-mechanical properties of epoxy network containing PMMA-modified silsesquioxane. Express Polymer Letters. 2009; 3(6):340-351. http://dx.doi.org/10.3144/ expresspolymlett.2009.43 